\title{
Journal of the International AIDS

\section{Increased risk for acute HIV infection from non-ulcerative STI's in MSM: aggressive STI eradication programs needed for reduction in HIV incidence}

\author{
RK Bolan ${ }^{1}$, SD Tilekar ${ }^{1}$, E Clay ${ }^{1}$, A Uniyal ${ }^{2}$, M Chein $^{2}$, PR Kerndt ${ }^{2}$ and \\ JD Scott*3
}

\begin{abstract}
Address: ${ }^{1}$ L.A. Gay \& Lesbian Center, Sexual Health Program, Los Angeles, USA, ${ }^{2}$ Los Angeles County Department of Public Health, Sexually Transmitted Disease Program, Los Angeles, USA and ${ }^{3}$ Western University of Health Sciences College of Pharmacy, Pomona, CA, USA

* Corresponding author
\end{abstract}

\author{
from Ninth International Congress on Drug Therapy in HIV Infection \\ Glasgow, UK. 9-13 November 2008 \\ Published: 10 November 2008 \\ Journal of the International AIDS Society 2008, I I (SuppI I):P303 doi:I0.I I86/I758-2652-I I-SI-P303
}

This abstract is available from: http://www.jiasociety.org/content/I I/SI/P303

(c) 2008 Bolan et al; licensee BioMed Central Ltd.

\section{Purpose of the study}

Clinical presentation of acute HIV infection is non-specific and may mimic sexually transmitted infections (STIs). Non-ulcerative STIs are prevalent among MSM. We examined the clinical presentation of acute HIV and sexually transmitted co-infections, and the role of non-ulcerative STIs in sexual acquisition of HIV infection.

\section{Methods}

9,058 persons testing HIV antibody negative were screened using a pooled HIV NAAT test (pool sizes varied from 24 to 90). STI testing of all at-risk anatomical sites was encouraged.

\section{Summary of results}

33 acute HIV infections were detected (positivity rate $0.36 \%)$. Of 31 patients concurrently tested, 19 (61.3\%) were co-infected with STIs: 13 (41.9\%) gonorrhea (2 urethral $/ 7 \mathrm{rectal} / 7$ pharyngeal); seven $(22.6 \%)$ chlamydia $(2$ urethral/7 rectal); two (6.5\%) syphilis; one $(3.2 \%)$ herpes, and eight $(25.8 \%)$ had two or more STI's. 24 saw a medical provider; only $46 \%$ reported symptoms and $21 \%$ had signs likely caused by HIV; $63 \%$ of symptoms and $67 \%$ of signs could be attributed to the STI. In $25 \%$ of cases there was significant overlap. Unexplained was the high rate of symptomatic oropharyngeal gonorrhea $(4 / 7$, or $57.1 \%$ ) as compared to $4 / 17$ (23.5\%) with pharyngitis but no gonococcus. Analysis was adjusted for age, sex, sex- ual orientation, sexual behavior, and the number of sexual partners in the last 3 months and in the last 30 days. There was a strong association between acute HIV infection and the presence of gonorrhea (OR $(95 \% \mathrm{CI}): 3.79$, 1.79 - 7.97); chlamydia (OR: $3.28,1.34-7.98)$, and chlamydia and/or gonorrhea (OR: 4.43, $2.13-9.22$ ). The population attributable risk (PAR) for HIV infection associated with gonorrhea was $32.4 \%$, chlamydia $16.8 \%$ and chlamydia and/or gonorrhea $44.2 \%$.

\section{Conclusion}

When acute HIV and an STI are co-infections, presenting signs/symptoms are more likely due to the STI than HIV, although non-specific symptoms consistent with Acute HIV Infection Syndrome can occur. Pharyngeal gonorrhea was often symptomatic in the setting of acute HIV. All atrisk anatomical sites should be tested for STIs. A high proportion of acute HIV infections in this MSM population are attributable to non-ulcerative STIs. Pooled NAATs for HIV and STI testing provide an opportunity for early HIV detection and STI treatment. For the HIV-negative individual, screening and treatment of STIs is crucial for HIV prevention. For the HIV-infected individual, the screening and treatment strategy will reduce further spread of HIV and STIs. 


\section{References}

I. Fleming DT, Wasserheit JN: From epidemiological synergy to public health policy and practice: the contribution of other sexually transmitted diseases to sexual transmission of HIV infection. Sex Transm Infect 1999, 75(1):3-17.

Publish with Bio Med Central and every scientist can read your work free of charge

"BioMed Central will be the most significant development for disseminating the results of biomedical research in our lifetime." Sir Paul Nurse, Cancer Research UK

Your research papers will be:

- available free of charge to the entire biomedical community

- peer reviewed and published immediately upon acceptance

- cited in PubMed and archived on PubMed Central

- yours - you keep the copyright

Submit your manuscript here:

http://www.biomedcentral.com/info/publishing_adv.asp 